\title{
Open BIM Standards: A Review of the Processes for Managing Existing Structures in the Pre- and Post-Earthquake Phases
}

\author{
Christian Musella *, Milena Serra, Antonio Salzano, Costantino Menna and Domenico Asprone \\ Department of Structures for Engineering and Architecture, University of Naples "Federico II", \\ 80125 Napoli, Italy; milena.serra@unina.it (M.S.); antonio.salzano@unina.it (A.S.); \\ costantino.menna@unina.it (C.M.); d.asprone@unina.it (D.A.) \\ * Correspondence: christian.musella@unina.it; Tel.: +39-081-7683471
}

Received: 4 September 2020; Accepted: 5 November 2020; Published: 21 November 2020

\begin{abstract}
The problem of managing existing structures before and after seismic events has led to the development of many different strategies across the globe. These aim to mitigate the catastrophic effects of earthquakes on the occupants of a building, as well as improve the management of the emergency that inevitably ensues. This paper explores the use of an openBIM approach to resolve the issues referred to above, which is possible because of two new standards: Industry Foundation Classes and Information Delivery Manuals. A review of the most popular strategies adopted in both the pre- and post-earthquake phases is conducted using a process map. This organizes the relevant steps and processes into tasks, and additionally identifies the points at which information is produced and exchanged and the party responsible for doing so. Also described is how BIM models can be utilized in essential pre- and post-earthquake activities, as well as current benefits and ongoing developments intended to improve the processes themselves.
\end{abstract}

Keywords: industry foundation classes; BIM model; information delivery manual; process map; seismic damage

\section{Introduction}

The management of existing structures is a topic of great importance and the subject of much research. In the countries most affected by severe earthquakes, like the USA, New Zealand and Italy, studies aim to assist those involved in the processes of ensuring the safety of a structure for its occupants and optimizing resources before an earthquake occurs and subsequently. Although many methodologies have been developed thus far, their very similar features mean that they can be applied to only two categories:

1. Preventative activities: these are carried out in the pre-earthquake period, and aim to guarantee safety during a seismic event and reduce repair costs as much as possible thereafter. As they are conducted in the absence of an emergency and on individual buildings, they are supported by very detailed analytical assessments, which are used to define ad hoc solutions and strategically optimize the resources required;

2. Processes to manage damaged buildings: these are carried out in the post-earthquake period, and require very rapid evaluations of a building's viability, equally fast interventions in the initial emergency phase, and more accurate assessments in the subsequent reconstruction stage.

All these processes have traditionally been carried out without the use of digital tools, or where their use is limited to individual, unconnected, activities. Lately, however, by integrating relevant steps 
and encouraging collaboration between the different actors involved in a project, the digital revolution of recent years aims to identify both inefficiencies in these processes and alternative ways of working.

Latterly, new digital procedures have been used to explore the ways in which Building Information Modelling (BIM) might assist in the field of structural engineering, in particular in relation to the processes utilized in the assessment and/or mitigation of seismic risk [1,2]. Ma et al. [3], for example, proposed an information model to facilitate the flow of data for post-earthquake assessments of reinforced concrete (RC) structures, basing their approach on typical damage modes and the existing Industry Foundation Class (IFC) schema. Other research uses BIM in the visual detection and identification of sources of vulnerability in structures, taking advantage of procedures that are minimally (or not at all) invasive [4], while some studies examine the application of BIM-based techniques to automate the generation of cost estimates related to seismic damage [5,6]. Additionally, beyond the well-known uses of BIM in project management, applications are also available in quantity surveying, process visualization and scheduling (4D), and cost estimation (5D), enabling integrated project deliveries $[7,8]$.

Taking advantage of new digital standards [9] and the increasing use of digital tools in the construction industry, this study aims to define optimized procedures for the management of existing structures. Also identified are features that it is hoped will be the subject of future research concerning the development of evermore mature digital processes. The paper has six sections: Section 2 describes the methodologies used to manage existing structures in the phases before and after the occurrence of a seismic emergency; Section 3 explains the role played by BIM models in enabling decisions to be made about any necessary interventions identified in all of the activities undertaken in the preand post-earthquake periods; Section 4 describes the elements comprising the Information Delivery Manual (IDM) standard. It also explains how a process map (PM) is developed to specify any necessary activities, as well as identify the points at which information is produced and the parties responsible for doing so. In Section 5, a proposal for the implementation of a post-earthquake process is described in detail, while Section 6 contains our deliberations on the maturity of current digital methodologies and the aspects requiring further work in the years to come.

\section{Processes for Managing Existing Structures}

\subsection{Preventive Activities}

Until recently, the performance required of ordinary buildings (i.e., non-strategic work for the community) was mainly limited to: containing the damage caused to non-structural components due to earthquakes that may strike on several occasions during the lifetime of a construction; and ensuring the safety of occupants during rare-occurrence events [10]. The structural response to seismic actions has typically been evaluated using linear or non-linear analyses that produce information on structural capacity. These data are expressed in terms of strength or displacement, and are compared with demand to determine the requirements for newly-designed buildings. There are additional prerequisites for both strategic buildings like hospitals [11] and general infrastructure in order to ensure their functionality during seismic events.

In recent years, however, scientific progress in relation to buildings has led to a requirement that economic factors should also be taken into account, particularly with respect to repair costs, which are the costs of restoring a building to its pre-earthquake condition, or, in the case of total loss, replacing it with a new structure with similar features [12]. This is known as the expected annual loss (EAL), whereby losses are broken down annually and expressed as a percentage of the reconstruction costs. This new parameter is particularly effective for communications with expert technicians, as well as with all the other stakeholders in a project, including the client making the final decisions. This new, wholly probabilistic, methodology is described as Performance-based Earthquake Engineering (PBEE), and is known as the PEER approach because it was developed by the Pacific Earthquake Engineering Research (PEER) Center. The methodology has four stages, as portrayed in Figure 1: 
1. Hazard analysis [13]—quantifying the intensity of potential seismic effects and the site-specific probability that those of a given intensity will occur;

2. Structural analysis-predicting a building's response to earthquake shaking, expressed in the form of response quantities (i.e., demands) that could be associated with structural and non-structural damage;

3. Damage analysis—described by probabilistic curves (known as fragility curves) [14]; these identify the probability of a specific level of damage as a function of an Engineering Demand Parameter (EDP) related to seismic actions;

4. Loss analysis-economic losses are estimated based on the performance of a structure.

Melani et al. [15] and Cardone et al. [16,17] have examined the EAL calculation for RC elements, while Kahre et al. adopted a similar approach to compare different types of RC walls. In these cases, the EAL values apply to each component investigated; when the same procedure is used for masonry structures, this value is applied to the building as a whole. Other relevant research includes a study by Bothara et al. [18], which focused on Unreinforced Masonry (URM), as well as work examining the application of the methodology to infrastructures like bridges [19]. The approach in these case studies produced rigorous results. However, because the methods are wholly probabilistic, they require considerable computational effort and a professional with significant expertise. As a consequence, this approach is now primarily used for research purposes, with very rare circumstances where it could be extended to more common applications. In some countries, however, this methodology is regarded as mature enough to be included in national codes and standards.

In Italy, the approach proposed by SismaBonus [20] takes into account both the vulnerability assessment and the EAL. In particular, the latter is determined using two different procedures: simplified, which is applicable to limited types of masonry buildings; and conventional, which can be used for any type of structure. Repair costs are fixed in advance and applied to an entire building. A seismic risk value from $A+$ (higher) to $G$ (lower) is identified for each of the two procedures, with the lower value taken to be representative of a building's performance. Perrone et al. [21] and Sullivan [22] have described simplified methods within this range of uses, which attempt to strike a proper balance between the accuracy of the method and the time available for its application. This has led to some authors [23] proposing a simplified approach that even considers the advantages of utilizing a BIM model. The first simplification, which is not wholly probabilistic, concerns the characterization of site hazards, and is based on evaluations of the inverse of the return period (TR). The main difference to the PEER methodology is in the structural analysis phase, where a static non-linear assessment is preferred to a non-linear time-history version. This approach has also been proposed by other authors [24] as a way to reduce the complexity of the process. In addition, the cost estimation is related to each component of a building, both structural and non-structural, while the Damage State (DS) is linked to parameters like inter-story drift or the spectral acceleration on each floor. The real advantage, therefore, is the fact that the method makes it possible to conduct evaluations of different intervention strategies and adopt the approach that minimizes costs and, as a result, has the lowest EALs.

\subsection{Post-Seismic Phase}

The post-earthquake stage is very different to that analysed above. In particular, there is no time to perform detailed post-emergency analyses because of the vastness of the real-estate assets involved and the need to provide speedy responses to owners about the accessibility, or not, of their properties. Accurate evaluations are, however, possible in the medium to long term.

The procedure in most common use today was first launched in the USA, and is described in the Applied Technology Council's ATC-20 guidelines [25], which were published in 1989 and regularly updated until 2005. These recommend that assessments should initially cover all the buildings located in the area affected by an earthquake, before then identifying and focusing resources on those posing the most risk to occupants. These analyses are therefore performed in three stages: 
1. Rapid evaluation;

2. Detailed evaluation;

3. Engineering analysis.

As is clear from their name, rapid assessments are brief, taking about 10-30 minutes per building. They are often cursory in nature, as their goal is to identify the presence or absence of hazardous conditions, particularly any earthquake-induced hazard that affects the safe occupancy of a structure. These hazards mainly involve structural or geotechnical (if recognizable) features that can be inspected with a rapid visual screening. In detail, this type of hazard can affect both an inspected building and neighbouring structures, and includes structural or foundation damage, damage to floors/roofs/walls, residual displacement, ground movement/settlement/slip, and overhead falling threats. The results of this inspection are communicated using a formal placard that employs a traffic-light type system that can be easily understood by even those with a non-technical background. The notice will state that a building:

1. Has been INSPECTED (green placard) - the damage does not pose any significant risk. This is only intended to notify people that the building is safe for occupation; it does not mean that any damage should be ignored or that repairs are unnecessary;

2. Is safe for RESTRICTED USE (yellow placard) — this addresses conditions where there are no clear safety concerns, but the damage identified precludes unrestricted occupancy. This notice is used if the evaluation reveals such damage that there should be no entry to part of a building, or where there is a restriction on the use or occupancy of the entire structure;

3. Is UNSAFE (red placard) - there is an immediate risk associated with entry, use or occupancy, denoting that going into a building is not permitted for any reason. This does not automatically mean that the property has been condemned or will require demolition.

These notices are generally placed at the entrance to a building or the part of it to which the sign refers. The placard also sets out any advice or possible action required to secure an area if it is thought to be unsafe. If assessors are unable to gain entry, the INSPECTED placard will state "Exterior Only." Rapid evaluations are helpful for systematically identifying the condition of a large number of buildings immediately following an earthquake, as well as for understanding the scale of the impact in terms of the damage to built assets.

Detailed evaluations are typically carried out on buildings awarded yellow and red notices following earlier assessments. A team of two structural engineers familiar with seismic design are responsible for completing this more in-depth investigation, which should include both exterior and interior inspections of the structural systems. The aim of this evaluation is to define the health status of a structure in relation to both gravity and lateral loads, and it may take between one and four hours, depending on the building's size and geometry. In most cases, this type of inspection does not need structural systems to be exposed, and structural drawings are likewise not required. The final stage, the engineering analysis, is mentioned in the ATC-20 guidelines, but no recommendations are made. In these circumstances, a building's owner would be expected to hire a contractor to perform detailed investigations, including material tests and structural surveys, in order to determine the appropriate retrofit interventions.

Although developed for use in the USA, the guidelines have been adopted by a number of countries, albeit with modifications. In New Zealand, for example, there are also three progressive levels and three colour tags:

1. A level 1 rapid assessment involves a brief external visual inspection of a building to assess the type and extent of its structural damage;

2. A level 2 rapid assessment is still relatively brief but, importantly, requires access to both the interior of a building for more extensive observations, as well any available drawings. This type of evaluation is typically required for all critical facility, multi-story, and other buildings where the level 1 process identifies the need for further and detailed inspections [26]; 
3. Level 3 in-depth engineering evaluations are usually carried out regardless of the outcomes of any level 1 or level 2 rapid assessments.

The third stage in New Zealand has two parts (qualitative and quantitative), and involves a full structural survey and the completion of a standardized spreadsheet [27]. The methodology was particularly valuable after the 2010 earthquake in Christchurch, with $80 \%$ of the 7922 [28] structures inspected tagged with a green placard. As only $20 \%$ of buildings required further investigation, emergency management resources could therefore be focused on them.

In Italy, the approach to a post-earthquake emergency is fairly similar, as the first rapid inspection aims to determine whether the short-term use of a building is possible. An example is the 2009 L'Aquila earthquake, where evaluations were initially carried out in less-damaged areas in order to both rapidly identify usable buildings and reduce the risk to inspectors from strong aftershocks; it was only after approximately two months that investigations were extended to the "red zones", i.e., the inaccessible areas. The assessment after this 2009 seismic event was conducted using the AeDES form [29], which has nine sections and contains information on a building's identification, dimensions, age, use, construction type and the damage sustained. The severity of the damage is described using visible indicators of the loss of performance, such as cracks, deflections, changes of geometry, separations of components, concrete spalling and the buckling of RC bars. The damage classification is based on its severity and extent, according to the European Macroseismic Scale [30]. The final judgement on immediate occupancy is not provided using a placard, but with letters from $\mathrm{A}$ to $\mathrm{F}(\mathrm{A}=$ usable; $\mathrm{B}=$ usable only after the implementation of short-term countermeasures; $\mathrm{C}=$ partially usable; $\mathrm{D}=$ requires reinspection; $\mathrm{E}=$ unusable; $\mathrm{F}=$ unusable, for external risk assessment only). A building can be used, even if it is slightly damaged, when it is given a category A classification. Categories $B$ and $C$ concern buildings with limited or no structural damage, but severe non-structural damage. If a building is in category $\mathrm{B}$, inspectors have to set out the short-term countermeasures required to enable its use, such as the removal of false ceilings or the propping of a lintel. In category $\mathrm{C}$, the possible partial or total collapse of a damaged part of a building is not an indication that any usable areas are unsafe [31].

This methodology was also used after the earthquake that struck central Italy in 2016. At the end of the seismic sequence in the historical centre of Norcia, $26 \%$ of 670 buildings under investigation were usable (A), $32 \%$ were unusable (E), and the remaining $42 \%$ were partially usable or required some short-term countermeasures. Sisti et al. [32] performed a number of calculations in their assessment of the inspected buildings, with their final report including their considerations on the impact of a building's position (isolated or aggregated), roof type, masonry quality and structural features.

\section{The Role of BIM Models in Pre- and Post-Earthquake Investigations}

Pre- and post-earthquake assessments have improved thanks to digital tools like BIM models [23,33], which link all of the tasks that must be performed in any investigations. Due to their complexity, we have summarized the two operational phases in Tables 1 and 2, respectively.

Table 1. List of pre-earthquake phases and activities.

\begin{tabular}{clll}
\hline \multicolumn{1}{c}{ Phase } & \multicolumn{1}{c}{ Activity } & \multicolumn{1}{c}{ Description } & \multicolumn{1}{c}{ Role } \\
\hline & Document research & $\begin{array}{l}\text { Researching documents, } \\
\text { graphics and pictures }\end{array}$ & $\begin{array}{l}\text { Structural engineer and } \\
\text { architect }\end{array}$ \\
\cline { 2 - 4 } $\begin{array}{c}\text { Knowledge of } \\
\text { the construction }\end{array}$ & Survey & $\begin{array}{l}\text { Survey of a building's } \\
\text { geometry }\end{array}$ & Surveying technician \\
\cline { 2 - 4 } & $\begin{array}{l}\text { Geometrical BIM } \\
\text { modelling }\end{array}$ & $\begin{array}{l}\text { Geometrical BIM } \\
\text { modelling using the } \\
\text { information previously } \\
\text { obtained }\end{array}$ & $\begin{array}{l}\text { Architectural BIM } \\
\text { modeller }\end{array}$ \\
\hline
\end{tabular}


Table 1. Cont.

\begin{tabular}{|c|c|c|c|}
\hline Phase & Activity & Description & Role \\
\hline \multirow{2}{*}{$\begin{array}{l}\text { Knowledge of } \\
\text { the construction }\end{array}$} & $\begin{array}{l}\text { Structural, geological } \\
\text { and geotechnical } \\
\text { investigations }\end{array}$ & $\begin{array}{l}\text { On-site and/or laboratory } \\
\text { material testing for the } \\
\text { mechanical evaluation } \\
\text { of materials }\end{array}$ & $\begin{array}{l}\text { Geologist, geotechnical } \\
\text { engineer and material- } \\
\text { testing technician }\end{array}$ \\
\hline & $\begin{array}{l}\text { Degradation and } \\
\text { damage detection }\end{array}$ & $\begin{array}{l}\text { Detection of the damage, } \\
\text { if any, affecting the } \\
\text { structural elements }\end{array}$ & $\begin{array}{l}\text { Structural engineer } \\
\text { and architect }\end{array}$ \\
\hline \multirow{3}{*}{ BIM modelling } & $\begin{array}{l}\text { Architectural BIM } \\
\text { modelling }\end{array}$ & $\begin{array}{l}\text { Upgrading the } \\
\text { architectural model }\end{array}$ & $\begin{array}{l}\text { Architectural BIM } \\
\text { modeller }\end{array}$ \\
\hline & $\begin{array}{l}\text { Structural BIM } \\
\text { modelling }\end{array}$ & Structural modelling & Structural BIM modeller \\
\hline & Clash detection & $\begin{array}{l}\text { Checking the accuracy of } \\
\text { the model }\end{array}$ & BIM coordinator \\
\hline Structural analysis & $\begin{array}{l}\text { Vulnerability and EAL } \\
\text { assessment }\end{array}$ & $\begin{array}{l}\text { Evaluation of the } \\
\text { structural performance } \\
\text { of a building's } \\
\text { current state }\end{array}$ & Structural engineer \\
\hline $\begin{array}{l}\text { Retrofit intervention } \\
\text { planning }\end{array}$ & Retrofit intervention & $\begin{array}{l}\text { Definition of any } \\
\text { intervention strategy } \\
\text { required to improve the } \\
\text { structural performance }\end{array}$ & $\begin{array}{l}\text { Structural engineer } \\
\text { and architect }\end{array}$ \\
\hline
\end{tabular}

The stages of the operations performed during the pre-seismic process can be classified in four ways:

1. Acquiring knowledge of a construction;

2. BIM modelling;

3. Structural analysis;

4. Retrofit intervention planning.

The starting point is acquiring the data that become the inputs in the definition of a BIM model. This is also known as "knowledge of the construction" [34] and has three phases:

1. A critical historical analysis to research documents, reports and available drawings;

2. A geometric structural survey to identify the load-bearing elements;

3. A mechanical characterization of materials, based on investigational assessments [35].

The expansion of the architectural BIM model begins in this phase, and is performed just after an in-situ survey to ensure that the precise geometry of a building is available for consideration. Any pathologies and degradations affecting the building's components are also identified in this phase, and are crucial for defining whether retrofit measures are required. This operation is often supported with specific datasheets created to store relevant information.

Depending on the quantity and detail of the investigations and tests carried out, a building is assigned a Level of Knowledge (LK): LK 1-limited investigations and tests have been performed; LK 2-these tests have been expanded; and LK 3 - the tests have been exhaustive. The LK thus provides an indication of the reliability of the information available on a structure. Downstream, knowledge of the construction enables the architectural model to be upgraded to ensure the availability of all of the information needed to perform the operations that follow. In this regard, the specification in ISO19650, which concerns the data required on BIM objects for use in subsequent tasks, introduced the notion of a Level of Information Needed (LOIN) as the specification for the data that BIM objects must obtain for subsequent tasks. 
Table 2. List of post-earthquake phases and activities.

\begin{tabular}{|c|c|c|c|}
\hline Phase & Activity & Description & Role \\
\hline \multirow{2}{*}{ Emergency } & Rapid evaluations & $\begin{array}{l}\text { Rapid visual check of the } \\
\text { structure, noting the } \\
\text { damage extent and } \\
\text { severity for an } \\
\text { accessibility assessment } \\
\text { of the building }\end{array}$ & Structural engineer \\
\hline & Detailed evaluations & $\begin{array}{l}\text { Detailed visual check of } \\
\text { the structure, noting the } \\
\text { damage extent and } \\
\text { severity for an } \\
\text { accessibility assessment } \\
\text { of the building }\end{array}$ & Structural engineer \\
\hline \multirow{5}{*}{ Engineering evaluations } & $\begin{array}{l}\text { Knowledge of } \\
\text { the construction }\end{array}$ & $\begin{array}{l}\text { Document research, } \\
\text { on-site surveys and } \\
\text { material testing }\end{array}$ & $\begin{array}{l}\text { Structural engineer } \\
\text { and architect }\end{array}$ \\
\hline & Damage detection & $\begin{array}{l}\text { Detection of collapsed } \\
\text { elements and the } \\
\text { extension and severity of } \\
\text { the crack pattern }\end{array}$ & Structural engineer \\
\hline & $\begin{array}{l}\text { Architectural BIM } \\
\text { modelling }\end{array}$ & $\begin{array}{l}\text { Architectural BIM } \\
\text { modelling of the } \\
\text { building and its damage }\end{array}$ & $\begin{array}{l}\text { Architectural BIM } \\
\text { modeller }\end{array}$ \\
\hline & $\begin{array}{l}\text { Structural BIM } \\
\text { modelling }\end{array}$ & Structural modelling & Structural BIM modeller \\
\hline & $\begin{array}{l}\text { Structural analysis and } \\
\text { retrofit interventions }\end{array}$ & $\begin{array}{l}\text { Definition of the } \\
\text { intervention strategy } \\
\text { needed to make the } \\
\text { structure safe }\end{array}$ & $\begin{array}{l}\text { Structural engineer } \\
\text { and architect }\end{array}$ \\
\hline
\end{tabular}

A structural BIM model can be created after the production of an architectural BIM model. However, before any data processing occurs, a clash-detection analysis of each of the models is required to verify their coherence. It is not necessary to conduct a clash-detection assessment of the relationship between the structural and architectural models, which are already coordinated because they are the outcomes of the survey of an existing building. An analytical model is then incorporated in the structural software, which then completes the modelling operation by introducing the mechanical proprieties, boundaries and load cases, and combinations. The mechanical behaviour of the building is therefore simulated based on the steps identified in Section 2.1. These processes aim to evaluate the performance of a building by calculating parameters like structural safety, displacements, or EALs. A determination is then made about whether retrofitting is required, before a plan is finally produced of the most effective intervention strategy.

Many of the considerations above are also valid in the post-earthquake stage (Table 2). One of the most relevant aspects in this phase involves the management of information relating to any damage affecting structural elements. The rapid and detailed evaluations conducted during an emergency produce information in either paper or digital form, because of the need for a quick response. As a result, BIM models are not used at the start of the process immediately after a seismic event. These rapid evaluations only take into account visible damage in the parts of a building that are accessible to inspectors, and relate solely to the damage's global severity and extent. Introducing BIM models during engineering evaluations enables the entire crack pattern to be digitalized when accurate inspections are carried out. It follows that the relevant properties are thoroughly defined and include accurate data on, for example, the width and direction of each crack and the phenomenon that caused the elements 
to fail. The process for completing the model in the post-earthquake phase is similar to that used in the pre-earthquake period, with the main difference being that the structural assessment of the DS is usually omitted in order to instead plan the retrofit interventions needed to make the building safe.

\section{The IDM Standard for Encoding a Structure's Management Processes}

All of the processes analysed thus far are codified in an IDM, which is an additional open standard produced by buildingSMART [36]. ISO 29481-1:2016 details [37] the IDM's methodology for defining and specifying processes and information flows during a facility's lifecycle. As described in "IDM: Guide to Components and Development Methods" [38], the methodology enables the integration of the processes and data required by the BIM model. This is achieved by identifying the discrete steps undertaken during the building's construction, the information needed to execute them and the results of that activity. In particular, the methodology specifies:

1. Where a step fits into the process and why it is relevant;

2. The actors involved in creating, utilizing and benefitting from the information produced;

3. What the information created and consumed actually is;

4. How the information can be supported with software solutions.

The IDM is specifically designed to separate the schema of an Industry Foundation Classes (IFC [39] into smaller, useful, but still related, elements. It is normally used when it becomes necessary to expand the IFC for specific uncodified BIM uses. Generally, the IFC schema provide a comprehensive specification for Architecture, Engineering, Construction and Facilities Management (AEC/FM) projects, capturing data from all the stakeholders involved (architects, engineers, constructors, facility managers etc.) during all the stages of a building's lifecycle, including initial requirements, design, construction, maintenance and operations.

It is important to note when considering the relationship between the IFC and IDM standards that the complete IFC schema is developed in the form of a set of individual topic schematics, each of which typically represents a consistent overall idea (e.g., structural analysis, cost, materials). Upon completion, all of these topic schemas are combined in a single plan, which is the authorized working version. This contains hundreds of entities (classes), data types and property sets (the IFC components) [40], and means that the IFC can support all the business requirements in all the project stages; in contrast, the IDM only supports one business requirement in one project stage (Figure 1).

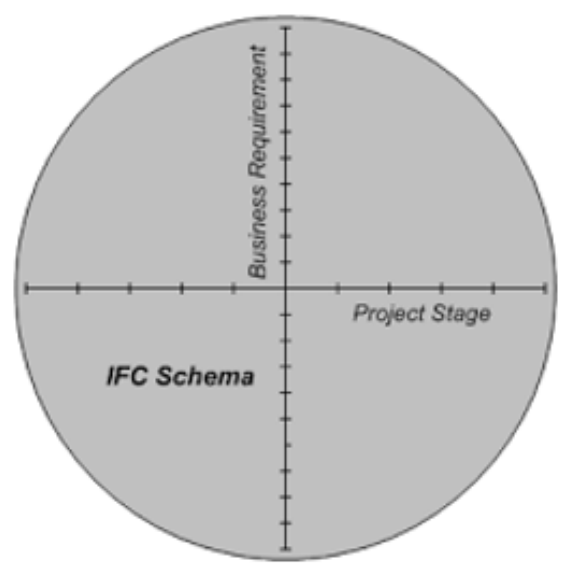

IFC supporting all business requirements at all project stages

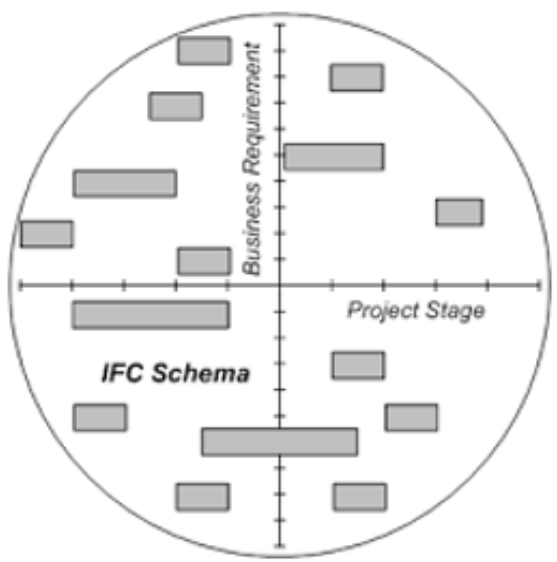

IDM supporting a business requirement at a project stage

Figure 1. IDM support for business processes [38]. 
The focus of the IDM on a particular topic enables it to define the data exchanged between the parties in each step and its level of detail, meaning that its involvement in the BIM stage is justified. In a Business Process (BP), deciding which IFC components should be used to satisfy the project's requirements is important for both BIM users (architect, engineer, constructor, etc.) and the creators of software solutions. This is crucial data for software users, who need to be sure that the IFC meets their requirements; meanwhile, solution providers have to be certain that the components meet the needs of their users (Figure 2).

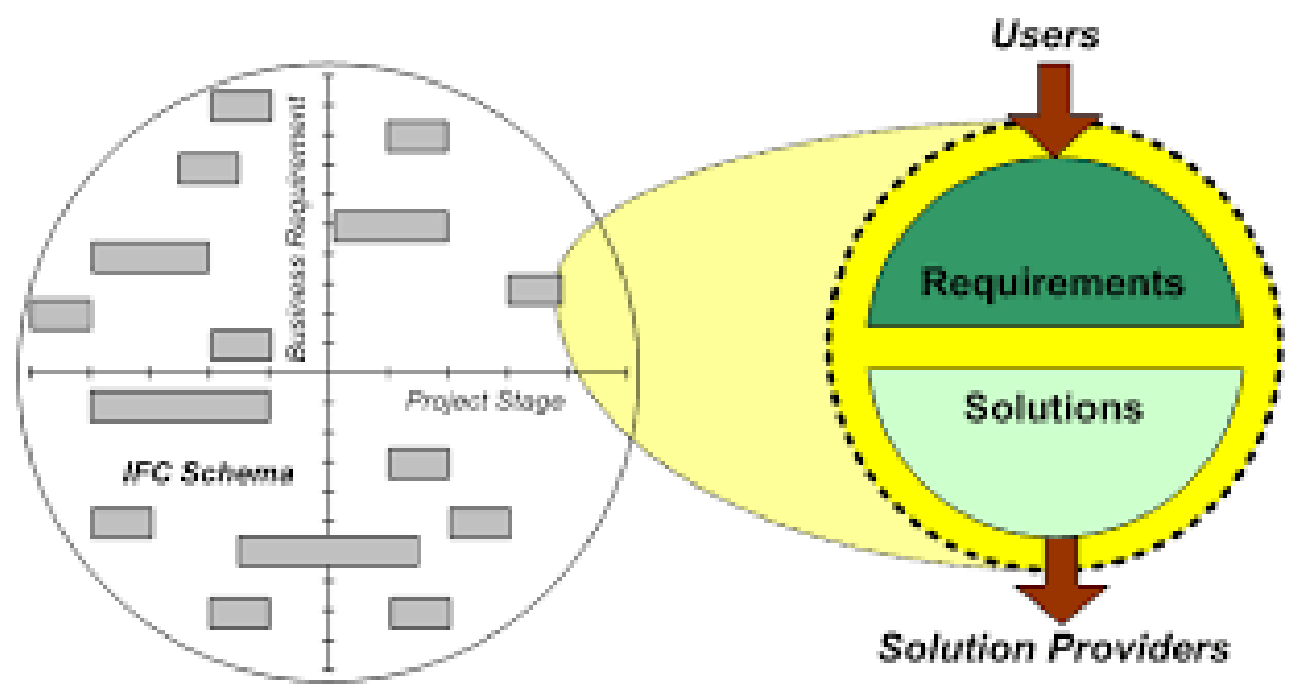

Figure 2. Business process requirements and solutions [38].

In more detail, an IDM has three parts: a Process Map (PM) [41], Exchange Requirements (ERs) [42] and Functional Parts (FPs). The PM consists of a flow-chart containing all the steps that must be undertaken throughout the process, as well as the connections between them. It also identifies the actors sending and receiving information within the process according to their role, and ensures that the definitions, specifications and descriptions are delivered in a suitable manner and are easy to understand by the members of a project's team. The PM highlights the ERs, i.e., the information contained within the IFC that needs to be exchanged to support the process. This data is in different file formats, such as BIM models, graphics, point clouds, pictures and reports. The FEs are the units of information used by solution providers to support an ER.

\section{Process Map}

The PM is the first part of the IDM and consists of a flow chart containing an accurate description of all the individual steps that comprise the entire process [43]. This is a very useful tool for information management, especially for the very complex processes in the construction industry, and also offers support to both BIM users and BIM software developers. In particular, it provides the former with an easily understandable and plain-language description of: the building construction processes; the details the information required to conduct the processes successfully; and the expected results of the processes themselves. This:

1. Makes information exchanges between a project's participants more reliable;

2. Improves the quality of information;

3. Improves decision making;

4. Enables a BIM project to be conducted much more effectively.

The PM is also valuable for BIM software developers, because it identifies and describes a detailed functional breakdown of the processes, as well as the IFC capabilities requiring support for each FP. This: 
1. Produces better responses to user needs;

2. Guarantees the quality of the information exchange;

3. Creates reusable software components.

As seen in Tables 1 and 2, all the tasks have been organized into project phases, meaning that they have been completely re-organized within a PM. The aim of the BP relates to the management of existing structures and is intended for use in the decision-making stage about a building. The graphical representation refers to the BP Model and Notation (BPMN) [44], which is a globally recognized methodology for specifying the BP in a BP model. Figure 3 only includes the PM for the post-earthquake phase; the one for the pre-earthquake period is a simplification of the version above and is obtained by excluding the tasks coloured in red in the figure. The steps in the PM are reported in the transverse direction to aid readability.

Many of the current methods analysed in Section 2 are implemented in the PM. The canvas for a map drawn with the BPMN consists of lanes and pools. The latter represent the organizations involved in a project, i.e., consultant, architectural, structural and the Common Data Environment (CDE) [45]. The lanes represent the individual participants, as well as their role within an organization when more than one professional from the same company is involved in the same process (e.g., BIM modeller, architect, structural engineer, geologist) [46]. The tasks that describe each operation performed by the respective skilled professionals are placed inside the pool. The lines denote the connections between the tasks and are represented by a continuous line when both the preceding and succeeding tasks are contained within the same pool; a dotted line is used when the flow connects one organization to another. Each information exchange between the parties is represented with the envelope symbol.

An analysis of the PM in Figure 3 highlights the clear definitions of the sequence of operations and the interchanging of the different professional profiles. The structural engineer starts the process, conducting rapid and detailed evaluations, and provides occupancy advice in relation to the building. The architect and survey technician perform the engineering evaluations and manage the document research and on-site survey. The information they collect enables the BIM modeller to build an initial architectural BIM model. All of the BIM objects are modelled by only taking into account the geometrical information, ensuring that the model is even able to provide support in the Knowledge Phase (KP). The information about the damage detected and the investigations conducted by the architect and structural engineer is centralized in a database. In the intervening period, the geologist and geotechnical engineer define and perform their respective investigations. Then, at the end of the $\mathrm{KP}$, the architectural model is upgraded with all the data collected for the LOIN. This can be used by the structural engineer to conduct the structural analysis required to assess the performance $(P)$ of the structure in relation to the safety index, displacements and EALs. The complete process is finalized when a decision is made about any required action. The process comes to an end by comparing $\mathrm{P}$ with the threshold values $\mathrm{P}^{*}$, based on the engineering evaluations or code recommendations; if this is not done, it would be necessary to plan retrofit interventions.

As the core of the BP concerns the structural discipline, it should be noted that obtaining the necessary background information means that most of the tasks are located in the structural engineer lane, with the other professionals having only a supporting role. Some of the tasks, in particular the survey, BIM modelling and retrofit interventions, are articulated in the sub-process, but this is not set out in the PM for reasons of clarity and to maintain the focus on the BP. Moreover, as shown in Figure 3, all the files exchanged during the process are located in the CDE pool. This has been subdivided into two lanes relating to the architectural data developed by the architect, as indicated by an A_number (A_1, A_2, ... A_8), and by an S_number $\left(S \_1, S \_2, \ldots\right.$, S8) for the structural data. The CDE is the virtual location where the information is stored and exchanged by the various team members. Each of the files in the CDE is an ER containing a precise set of data that must be explained in the IDM. 


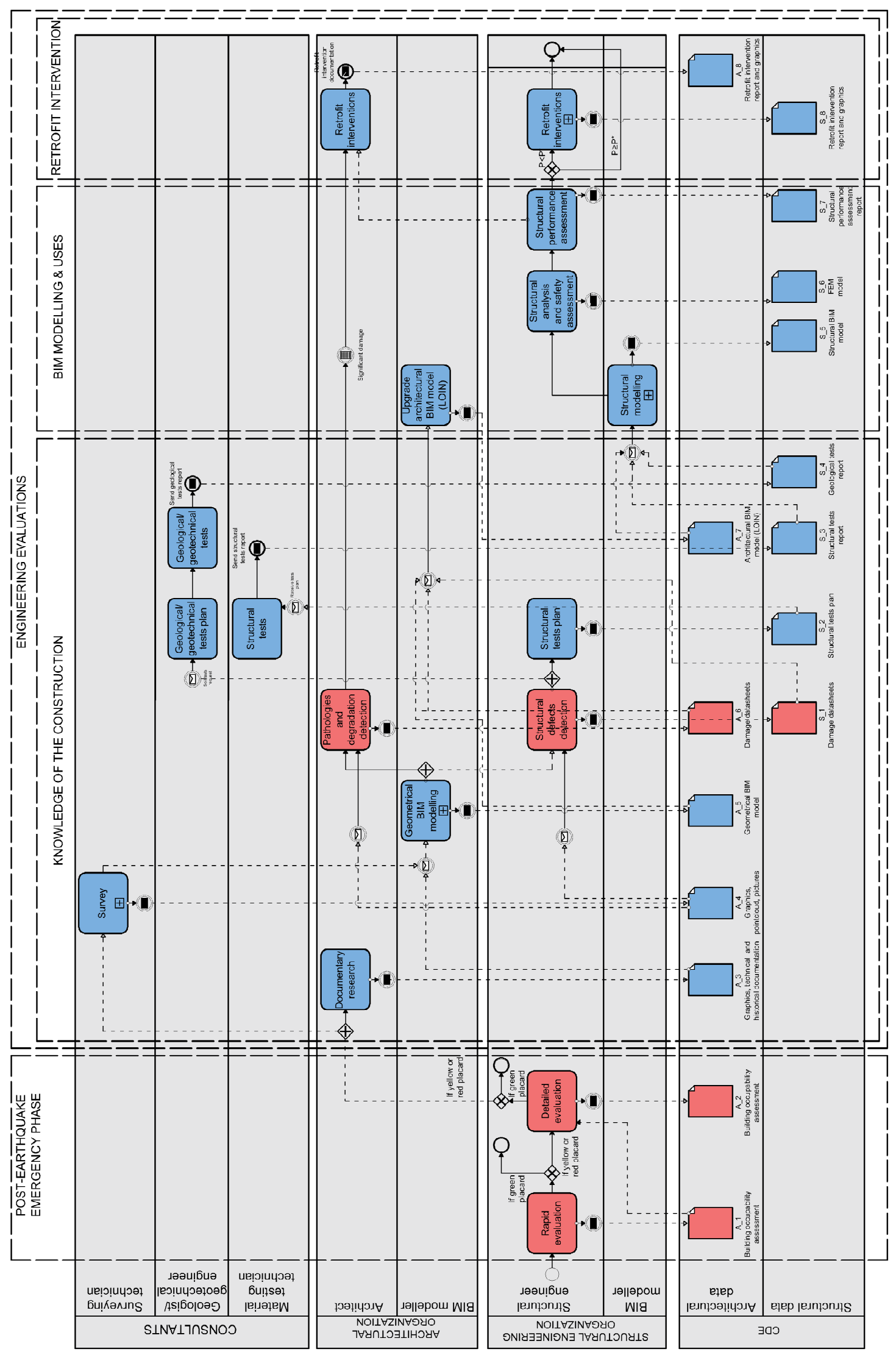

Figure 3. The process map for managing existing structures in the post-earthquake phase. 


\section{Application of the Procedure Using Open BIM Standards in a Case Study of Palazzo Penne}

The methodology discussed in this paper has been used in the renovation of Palazzo Penne, a renaissance masonry palace built in 1406 and located in the historical centre of Naples (Figure 4). The palace is an example of civilian habitation in the $\mathrm{XV}$ century, and is one of the few constructions that did not collapse after the devastating earthquake of 1456 . As a consequence, it requires an analysis of its crack patterns and the damage suffered due to this and other seismic events. The renovation project was described some years ago in the traditional manner, with extensive and accurate documentation made available relating to all the phases, ranging from the acquisition of information on the mechanical properties of the materials to the geometry of the construction and the design of the retrofit interventions. In fact, thanks to the large amount of documentation available, the proposed digital and innovative method discussed herein has been simulated as a way to test an accurate and transparent example of information management. However, technological deficiencies mean that the process described cannot currently be wholly implemented digitally, even in relation to the IFC standard. Accordingly, a possible solution to these issues has been produced using available tools and is described below.
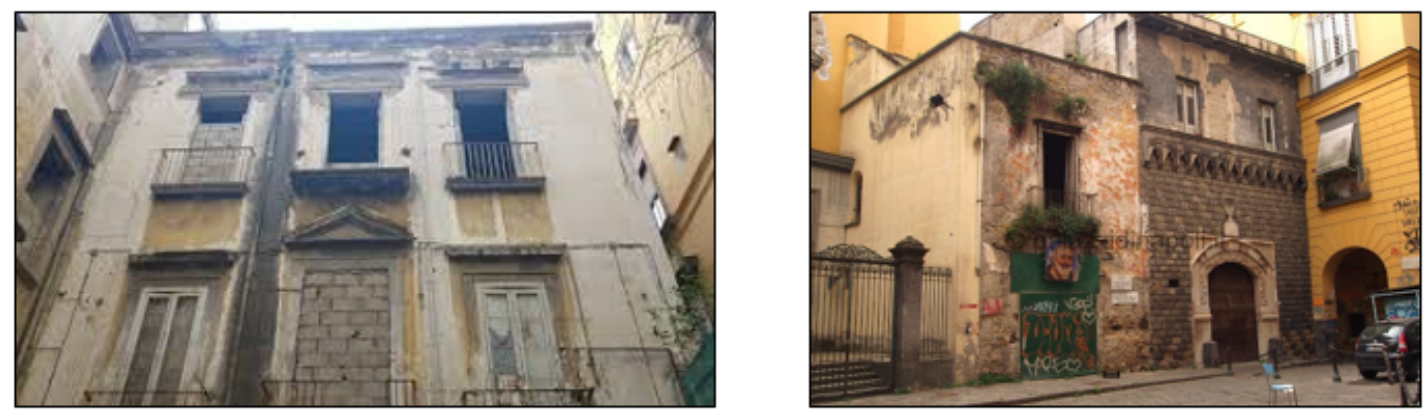

Figure 4. Palazzo Penne building.

\subsection{BIM Modelling and Management}

Generally, due to the complex geometry of historical buildings like Palazzo Penne, the traditional method is difficult to implement at the start of a geometric survey. The digital approach proposed in this paper is a solution to this issue. Indeed, in relation to survey activities, the operation is simplified through the support provided by modern technologies that enable the elaboration of point clouds that reproduce the $3 \mathrm{D}$ geometry of a building.

In more detail, 2D drawings (including sections, plans and elevations) have been extracted from the building's point cloud, which was derived from the digital survey and used to create the BIM model of the palace (Figure 5). Many difficulties arose during the modelling process, because the available BIM-authoring software was developed for use in the design of new constructions. This means that even the modelling operation is difficult to carry out for an existing structure, in particular because of the uniqueness and complexity of each element, which barely meets the definition of a "parametric object".
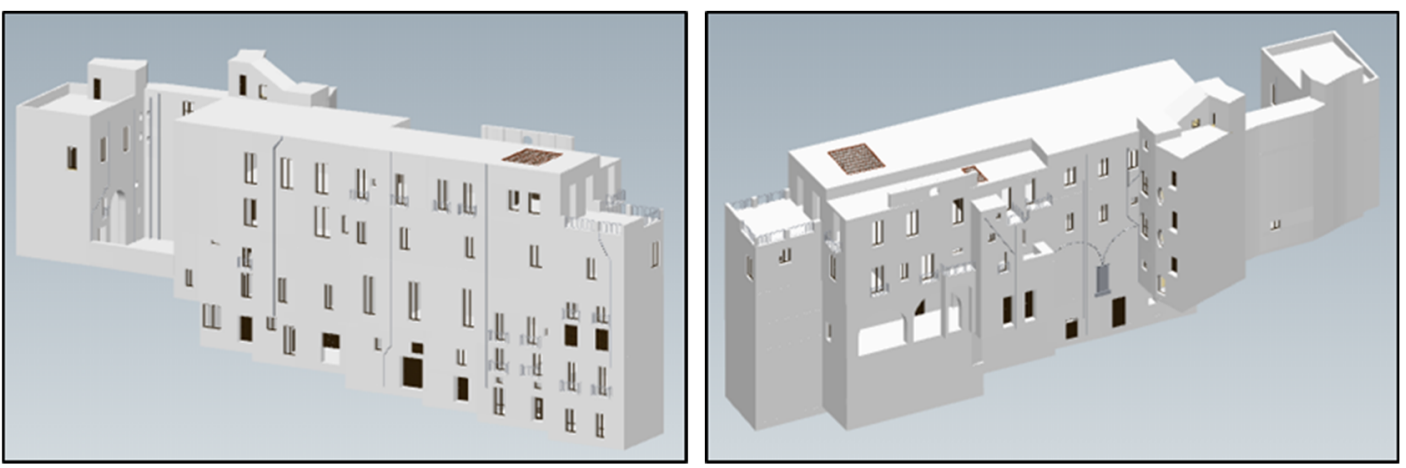

Figure 5. Palazzo Penne BIM model. 
Once the model was completed, and similar to the traditional methodology, the digital process included specialist surveys whereby the structural engineer performed the investigations required to define the mechanical properties of the materials and detect the cracks and collapses affecting the structure; meanwhile, the architect provided reports on the damage and degradation.

However, unlike the traditional process, and thanks to the usBIM.platform developed by ACCA Software, much of the information collected on site could be digitalized using dedicated tools. The aim was to aggregate the information in both the model and documents of a different nature. In this regard, using the online viewer usBIM.browser, which is a tool directly linked to the platform, numerous reports, point clouds and files (even those in different formats) were linked to the model directly within the CDE (Figure 6). In more detail, the damage and degradation datasheets, as well as the mesh models of any elements of architectural value in Palazzo Penne (like the front door and the façade ashlars with the coats of arms of d'Angiò and Penne), were directly linked to the BIM objects in the model to which they refer.

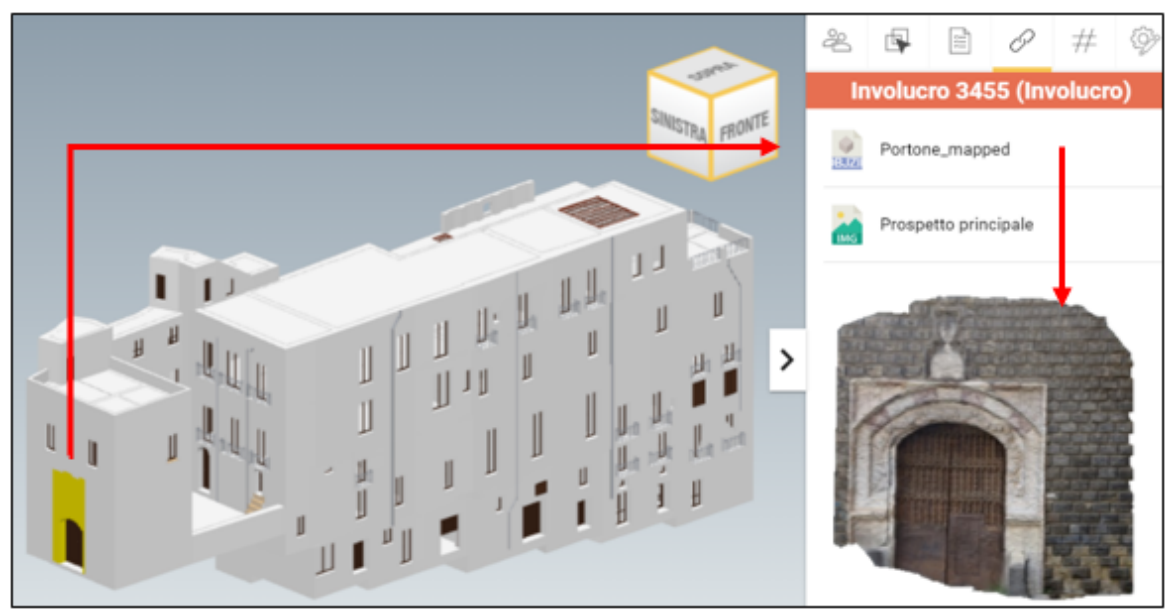

Figure 6. Links between the documents in the Common Data Environment of Palazzo Penne.

Pointers were then added to the model to identify the data collected, making it quick and easy to navigate and visualize the information now available. In this regard, in order to visualize the damage, and given the study's goal, i.e., the management of existing structures before and after seismic events, the structural engineer located photos of the endoscopy of the walls and its identification number, while the architect unearthed images of the inspected degradation (Figure 7).

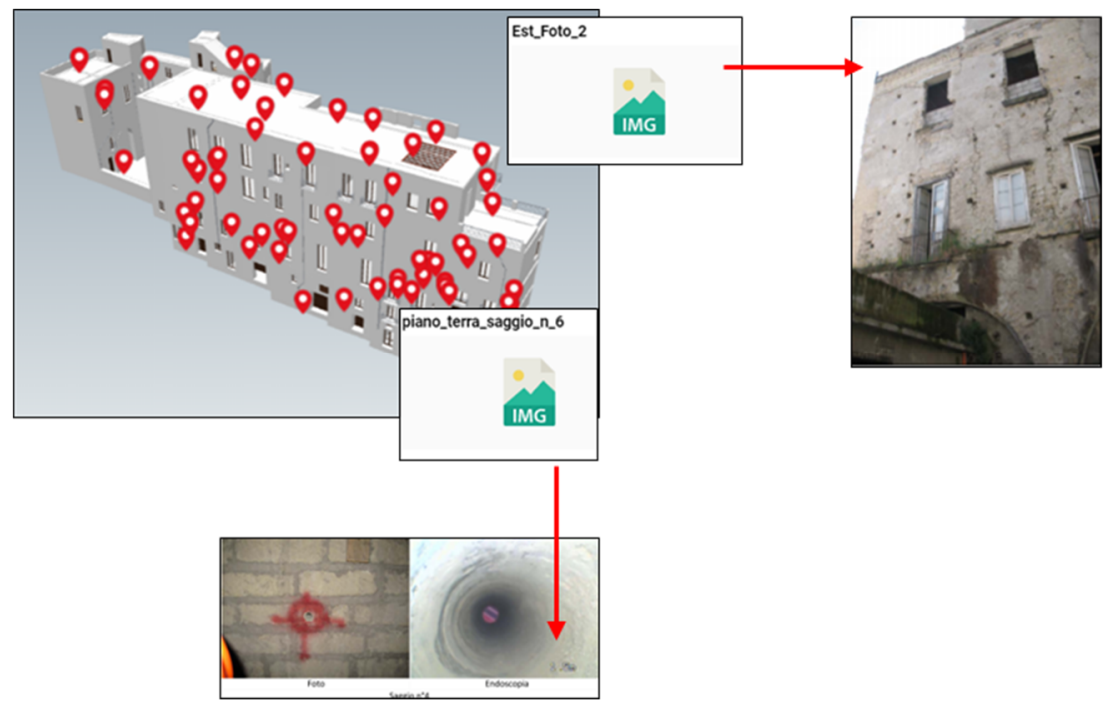

Figure 7. Links between the documents in the Common Data Environment of Palazzo Penne. 
In addition, a further marker, known as \#tagBIM, was added to the model's objects and proved to be particularly useful for quickly browsing the information available. In more detail, the information with the \#tagBIM marker pertained to the damage inspected and the investigations performed. As shown in Figure 8, the options provided by the \#tagIM marker enabled all of this information to be cross-checked and, as a result, facilitated the research activities.

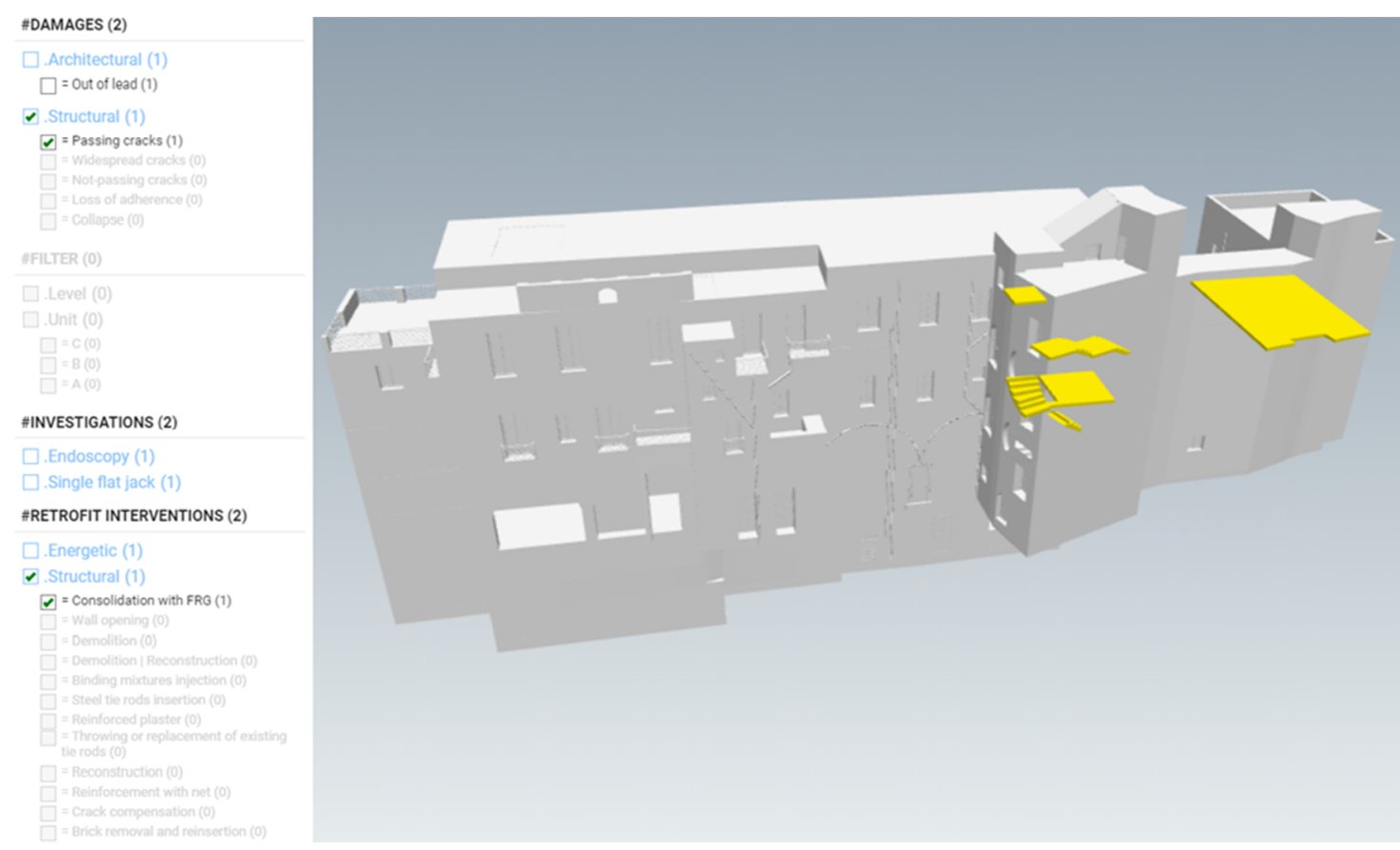

Figure 8. \#TagBIM of the BIM model's objects of Palazzo Penne.

Consequently, these tools mean that the information can be "Googled" directly from an online browser, enabling the files to be identified and the documents linked to their respective objects.

\subsection{Implementation of Digital Datasheets for the Collection of Information}

In many of the operations typically carried out during KPs, information is collected about a building and its current state, often through the use of synthetic sheets. In traditional processes, these forms are paper-based and, often at a later stage, are scanned or even copied in an IT environment, leading to inefficiencies within the operation. Thanks to digital applications, information in the form of data can be collected during inspections and stored within the platform for immediate use. These forms are directly associated with the IFC elements of the models to which they refer. They can also be completed with information that is not expressly codified in the IFC standard, but is nevertheless required to carry out the operations.

In relation to Palazzo Penne, these tools were used to define datasheets for the digitalization of the crack pattern, and were created while taking into account many of the parameters included in a variety of standards, including:

- AEDES sheets;

- Lessico normal 1/88;

- Abacus of decays;

- "Provisions concerning the post-seismic activity findings resulting from seismic events that affected the territory of the regions of Lazio, Marche, Umbria and Abruzzo on 24 August 2016", Ordinance No. 10 of 19 December 2016 and s.m.i. (trad. "Disposizioni concernenti i rilievi di agibilità post sismica conseguenti agli eventi sismici che hanno colpito il territorio delle Regioni Lazio, Marche, Umbria e Abruzzo a partire dal giorno 24 agosto 2016", Ordinanza n. 10 del 19 December 2016 and s.m.i.) 
- Directive of the Minister of Cultural Heritage, Activities and Tourism-Addition to the Directive of 12 December 2013-"Procedures for the management of activities to make safe and safeguard cultural heritage in the event of emergencies resulting from natural disasters" (trad. Direttiva del Ministro dei beni e delle attività culturali e del turismo-Aggiornamento della direttiva del 12 dicembre 2013- "Procedure per la gestione delle attività di messa in sicurezza e salvaguardia del patrimonio culturale in caso di emergenze derivanti da calamità naturali".)

Set out below is an example of the datasheet that can be completed on site with the aid of a tablet or smartphone (Figure 9).

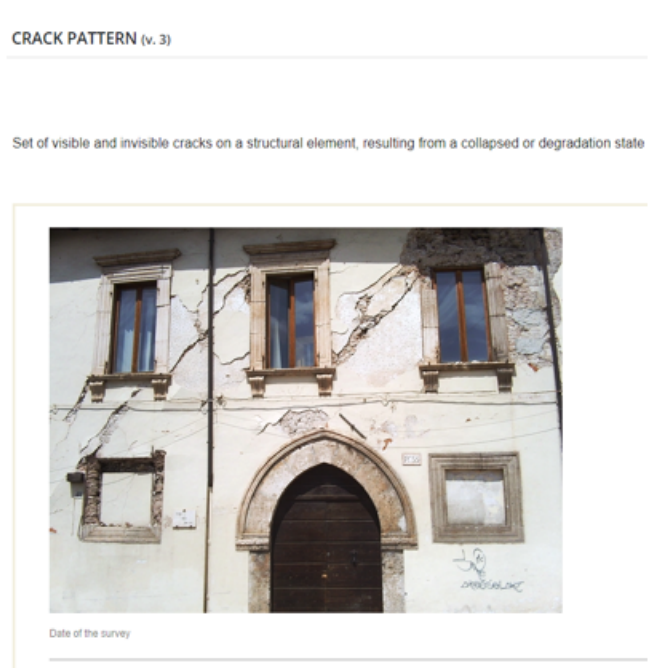

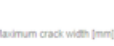

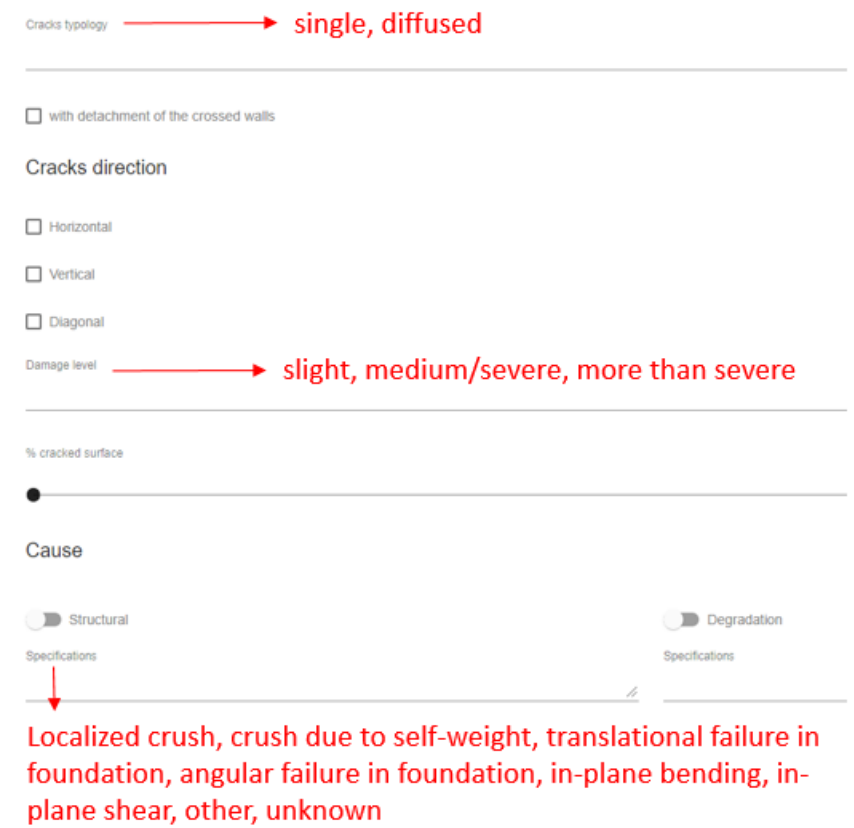

Figure 9. Crack-pattern datasheet.

These datasheets not only support the process for defining the DS at the time of the survey, but can also be used to monitor the ongoing collection of the information employed to track the possible progression of the damage. Moreover, thanks to their implementation in IFC models, there is no relationship with the BIM-authoring software used for the modelling, meaning that the process can be carried out according to openBIM principles.

\section{The Digital Maturity of the Processes for Managing Existing Structures}

The need to digitalize the management of existing structures is not new in the research field. Dong et al. [47], for instance, have described an extensive case history of the various techniques developed for pre- and post-event actions in relation to different types of data. In more detail, examples are studies that have led to: the creation of digital tools to support the rapid risk assessment of structures on a large scale [48]; and the use of multi-temporal satellite imagery techniques that enable the areas where the greatest damage has occurred to be detected in the post-earthquake period [49].

Intentionally highlighted in the passages above is the need for a strategy that involves all the activities and professionals participating in a project. To this end, the IFC and IDM standards provide relevant support, as they were developed to improve collaboration during ventures. However, it should be noted that the digital processes are not as effective as desired in relation to information exchanges, due to problems of software interoperability and the structure of the IFC schema, which have not yet achieved sufficient maturity. These issues concern both pre- and post-earthquake processes. One of the main reasons for such problems in the pre-seismic event stage is that the IFC standard, although a valid 
starting point for the integration of structural processes with other disciplines involved in building management, is not yet fully interoperable.

In this context, it has to be assumed that the structural analysis tool is capable of exchanging both incoming and outgoing information in the central database, i.e., the BIM model. The generation and transfer of the Finite Element Model (FEM) from the BIM model to the analysis software are delicate operations. They cannot, however, be conducted using open tools like IFCs, with reliance instead on ad hoc procedures or those that are only optimized to work within digital ecosystems created by individual software providers. This is partly because an analytical model cannot always be defined unambiguously, causing problems for coding operations. In addition, the structural performances are not actually coded at all within the IFC structure, which comprises objects, the relationships between them and properties. It may, therefore, be useful to expand the set of properties to include parameters that represent structural performance, including displacements or the work ratios of the elements. There is a further difficulty (still unresolved) regarding the inputting of parameters that characterize the behaviour of an entire structure, with examples being the safety index, EALs and the frequencies of vibration modes.

This is not an exhaustive review of the problems faced: post-earthquake processes have further critical issues in relation to the coding of seismic damage. Furthermore, the IFC standard covers neither properties relating to the DS of components, nor BIM objects specific to the virtualization of any damage, i.e., cracks and degradation phenomena. These properties are required to conduct the operations referred to in Section 2, in particular assessments of the DS of these elements and an entire building. Moreover, the operations performed on damaged buildings often require the use of only paper-based forms to collect information on site. In this regard, digital archive management is one of the most promising aspects of BIM, given the high volume of forms that are commonly produced. The relevance of the matter is also emphasized by the fact that the IFC standard only enables the exchange of data, not documents, making it necessary to provide alternative solutions. The use of digital forms would facilitate the creation of central databases in which information is collected as easy-to-use data. At present, thanks to the integration of multiple types of data, a BIM model could be described as an informative model in which virtualization not only produces a 3D representation of a building, but is also a reference point for all the stakeholders involved in a project.

\section{Conclusions}

This paper has analysed the processes usually involved in the management of existing structures. In particular, two stages are outlined: 1. pre-earthquake, in which the behaviour of structures during seismic events is evaluated using representative parameters (i.e., displacements, the safety index and EALs); and 2. post-earthquake, where the process aims to define a risk scale for use when planning retrofit interventions. As the aim of the study was to define an effective procedure for managing these processes digitally, our investigation covered the roles played by BIM models and IDM standards. After defining all the roles involved in these processes, a PM was developed using the BPMN language and according to the IDM standard, which organizes and synthesizes all the activities carried out, highlighting which party is responsible for each of them. A PM encourages collaborative working and information exchanges between various professionals, reducing the likelihood of mistakes. Moreover, activity planning facilitates reflections on opportunities to use digital tools to optimize current work practices.

Our study used the IFC standard to implement the process for managing an existing building in the post-earthquake phase. In detail, the BIM model of the building was uploaded in a collaborative platform and used as a store for all the data produced during the process. Indeed, the BIM model, rather than a mere 3D representation of the building, became the key access point for all the information collected in the CDE, enabling the management of a huge amount of previously fragmented data. In particular, the pointers and the \#tagBIM marker meant that all the information was centralized in 
the BIM model, which then acted as a point of reference for every team member and provided ongoing support for their activities.

Author Contributions: Investigation, M.S.; Methodology, C.M. (Christian Musella); Supervision, C.M. (Costantino Menna) and D.A.; Writing - original draft, A.S. All authors have read and agreed to the published version of the manuscript.

Funding: The activities described in this paper form part of work being carried out under the auspices of the research grant: BIM ReCulT (Il metodo BIM per il Recupero del patrimonio CulTurale).

Conflicts of Interest: The authors have no conflicts of interest to declare.

\section{References}

1. Welch, D.P.; Sullivan, T.J.; Filiatrault, A. Potential of Building Information Modelling for seismic risk mitigation in buildings. Bull. N. Z. Soc. Earthq. Eng. 2014, 47, 253-263. [CrossRef]

2. Maio, R.; Santos, C.; Ferreira, T.M.; Vicente, R. Investigation Techniques for the Seismic Response Assessment of Buildings Located in Historical Centers. Int. J. Arch. Herit. 2018, 12, 1245-1258. [CrossRef]

3. Ma, L.; Sacks, R.; Zeibak-Shini, R. Information modeling of earthquake-damaged reinforced concrete structures. Adv. Eng. Inform. 2015, 29, 396-407. [CrossRef]

4. Garavaglia, E.; Anzani, A.; Maroldi, F.; Vanerio, F. Non-Invasive Identification of Vulnerability Elements in Existing Buildings and Their Visualization in the BIM Model for Better Project Management: The Case Study of Cuccagna Farmhouse. Appl. Sci. 2020, 10, 2119. [CrossRef]

5. Christodoulou, S.E.; Vamvatsikos, D.; Georgiou, C.A. BIM-Based Framework for Forecasting and Visualizing Seismic Damage, Cost and Time to Repair. In eWork and eBusiness in Architecture, Engineering and Construction; Scherer, R.M., Ed.; Taylor \& Francis Group: London, UK, 2010; pp. 33-38. ISBN 978-0-415-60507-6. Available online: https://ktisis.cut.ac.cy/handle/10488/14303 (accessed on 3 November 2020).

6. $\mathrm{Xu}, \mathrm{Z}$; $\mathrm{Lu}, \mathrm{X}$.; Zeng, X.; Xu, Y.; Li, Y. Seismic loss assessment for buildings with various-LOD BIM data. Adv. Eng. Inform. 2019, 39, 112-126. [CrossRef]

7. Mellado, F.; Wong, P.F.; Amano, K.; Johnson, C.; Lou, E.C. Digitisation of existing buildings to support building assessment schemes: Viability of automated sustainability-led design scan-to-BIM process. Arch. Eng. Des. Manag. 2019, 16, 84-99. [CrossRef]

8. Godinho, M.; Machete, R.; Ponte, M.; Falcão, A.P.; Gonçalves, A.B.; Bento, R. BIM as a resource in heritage management: An application for the National Palace of Sintra, Portugal. J. Cult. Herit. 2020, 43, 153-162. [CrossRef]

9. Patacas, J.; Dawood, N.; Kassem, M. BIM for facilities management: A framework and a common data environment using open standards. Autom. Constr. 2020, 120, 103366. [CrossRef]

10. Calvi, G.M.; Pinho, R.; Magenes, G.; Bommer, J.J.; Restrepo-Vélez, L.F.; Crowley, H. Development of seismic vulnerability assessment methodologies over the past 30 years. ISET J. Earthq. Technol. 2006, 43, 75-104.

11. Filiatrault, A.; Lee, G.; Aref, A.; Bruneau, M.; Constantinou, M.C.; Reinhorn, A.M.; Whittaker, A. Recent progress towards the seismic control of structural and non-structural systems in hospitals. In Proceedings of the US-Japan 36th Technical Meeting of Panel on Wind and Seismic Effects, Washington, DC, USA, 17-22 May 2004.

12. FEMA-P58. Seismic Performance Assessment of Buildings-Volume 1: Methodology; Federal Emergency Management Agency: Washington, DC, USA, 2008.

13. McGuire, R.K. Probabilistic seismic hazard analysis: Early history. Earthq. Eng. Struct. Dyn. 2008, 37, 329-338. [CrossRef]

14. Shinozuka, M.; Feng, M.Q.; Lee, J.; Naganuma, T. Statistical Analysis of Fragility Curves. J. Eng. Mech. 2000, 126, 1224-1231. [CrossRef]

15. Melani, A.; Khare, R.; Dhakal, R.; Mander, J.B. Seismic risk assessment of low rise RC frame structure. Structures 2016, 5, 13-22. [CrossRef]

16. Cardone, D.; Flora, A. Direct displacement loss assessment of existing RC buildings pre- and post-seismic retrofitting: A case study. Soil Dyn. Earthq. Eng. 2014, 64, 38-49. [CrossRef]

17. Cardone, D.; Perrone, G. Damage and Loss Assessment of Pre-70 RC Frame Buildings with FEMA P-58. J. Earthq. Eng. 2016, 21, 23-61. [CrossRef] 
18. Bothara, J.; Mander, J.B.; Dhakal, R.P.; Khare, R. Seismic performance and financial risk of masonry house. ISET J. Earthq. Technol. 2007, 421-444. Available online: https://ir.canterbury.ac.nz/handle/10092/4442 (accessed on 3 November 2020).

19. Solberg, K.M.; Dhakal, R.P.; Mander, J.B.; Bradley, B.A. Computational and rapid expected annual loss estimation methodologies for structures. Earthq. Eng. Struct. Dyn. 2007, 37, 81-101. [CrossRef]

20. European Commission. Urgent Provisions for the Transposition of Directive 2010/31/EU of the European Parliament and of the Council of 19 May 2010 on the Energy Performance of Buildings for the Definition of Infringement Procedures Initiated by the European Commission, as Well as Other Provisions on Social Cohesion (Trad. "Disposizioni Urgenti per il Recepimento della Direttiva 2010/31/UE del Parlamento Europeo e del Consiglio del 19 Maggio 2010, Sulla Prestazione Energetica Nell'edilizia per la Definizione delle Procedure D'infrazione avviate dalla Commissione Europea, Nonche' Altre Disposizioni in Materia di Coesione Sociale"); European Commission: Brussels, Belgium, 2010; D.L. 63/2013 e ss.mm.ii. (s.d.).

21. Perrone, G.; Cardone, D.; O’Reilly, G.J.; Sullivan, T.J. Developing a Direct Approach for Estimating Expected Annual Losses of Italian Buildings. J. Earthq. Eng. 2019, 1-32. [CrossRef]

22. Sullivan, T. Use of Limit State Loss versus Intensity Models for Simplified Estimation of Expected Annual Loss. J. Earthq. Eng. 2016, 20, 954-974. [CrossRef]

23. Vitiello, U.; Ciotta, V.; Salzano, A.; Asprone, D.; Manfredi, G.; Cosenza, E. BIM-based approach for the cost-optimization of seismic retrofit strategies on existing buildings. Autom. Constr. 2019, 98, 90-101. [CrossRef]

24. Cardone, D.; Sullivan, T.; Gesualdi, G.; Perrone, G. Simplified estimation of the expected annual loss of reinforced concrete buildings. Earthq. Eng. Struct. Dyn. 2017. [CrossRef]

25. Rojahn, C. Procedures for Post-Earthquake Safety Evaluation of Buildings; Applied Technology Council (ATC): Redwood City, CA, USA, 1989.

26. Galloway, B.D.; Hare, H.J. A Review of Post-Earthquake Building Control Policies with Respect to the Recovery of the Christchurch CBD; Annual Bulletin of the New Zealand Society for Earthquake Engineering (NZSEE): Christchurch, New Zealand, 2012; pp. 105-116.

27. Marquis, F.; Kim, J.J.; Elwood, K.J.; Chang, S.E. Understanding post-earthquake decisions on multi-storey concrete buildings in Christchurch, New Zealand. Bull. Earthq. Eng. 2015, 15, 731-758. [CrossRef]

28. Marshall, J.D.; Jaiswal, K.; Gould, N.C.; Turner, F.; Lizundia, B.; Barnes, J.C. Post-Earthquake Building Safety Inspection: Lessons from the Canterbury, New Zealand, Earthquakes. Earthq. Spectra 2013, 29, 1091-1107. [CrossRef]

29. Goretti, A.; Di Pasquale, G. An Overview of Post-Earthquake Damage Assessment in Italy; EERI: Pasadena, CA, USA, 2002.

30. Grunthal, G. Cahiers du Centre Européen de Géodynamique et de Séismologie. European Macroseismic Scale; European Center for Geodynamics and Seismology: Luxembourg, 1998.

31. Dolce, M.; Goretti, A. Building damage assessment after the 2009 Abruzzi earthquake. Bull. Earthq. Eng. 2015, 13, 2241-2264. [CrossRef]

32. Sisti, R.; Di Ludovico, M.; Borri, A.; Prota, A. Damage assessment and the effectiveness of prevention: The response of ordinary unreinforced masonry buildings in Norcia during the Central Italy 2016-2017 seismic sequence. Bull. Earthq. Eng. 2018, 17, 5609-5629. [CrossRef]

33. Ma, L.; Sacks, R.; Zeibak-Shini, R.; Aryal, A.; Filin, S. Preparation of Synthetic As-Damaged Models for Post-Earthquake BIM Reconstruction Research. J. Comput. Civ. Eng. 2016, 30, 04015032. [CrossRef]

34. Eurocode 8-3-Design of Structures for Earthquake Resistance-Assessment and Retrofitting of Buildings. Available online: https://en.wikipedia.org/wiki/Eurocode_8:_Design_of_structures_for_earthquake_resistance (accessed on 6 November 2020).

35. Honic, M.; Kovacic, I.; Sibenik, G.; Rechberger, H. Data-and stakeholder management framework for the implementation of BIM-based Material Passports. J. Build. Eng. 2019, 23, 341-350. [CrossRef]

36. buildingSMART International. Available online: https://www.buildingsmart.org/standards/bsi-standards/ information-delivery-manual/ (accessed on 3 November 2020).

37. ISO 29481-1:2016. Building Information Models_Information Delivery Manual-Part 1: Methodology and Format. 2016. Available online: https://www.iso.org/standard/60553.html (accessed on 6 November 2020).

38. Wix, J.; Karlshøj, J. Information delivery manual: Guide to components and development methods. buildingSMART Int. 2010, 5, 10. 
39. ISO 16739-1:2018. Industry Foundation Classes (IFC) for Data Sharing in the Construction and Facility Management Industries_Part 1: Data Schema; ISO: Geneva, Switzerland, 2018.

40. Venugopal, M.; Eastman, C.; Sacks, R.; Teizer, J. Semantics of model views for information exchanges using the industry foundation class schema. Adv. Eng. Inform. 2012, 26, 411-428. [CrossRef]

41. Voss, E.; Jin, Q.; Overend, M. A BPMN-based process map for the design and construction of façades. J. Facade Des. Eng. 2013, 1, 17-29. [CrossRef]

42. Lee, Y.-C.; Eastman, C.M.; Solihin, W. An ontology-based approach for developing data exchange requirements and model views of building information modeling. Adv. Eng. Inform. 2016, 30, 354-367. [CrossRef]

43. Wu, W.; Issa, R. Integrated process mapping for BIM implementation in green building project delivery. In Proceedings of the 13th International Conference on Construction Applications of Virtual Reality, London, UK, 30-31 October 2013; pp. 30-39.

44. Tsai, Y.-H.; Hsieh, S.-H. Process modeling of a BIM-enabled construction inspection approach with BPMN. In Proceedings of the International Conference on Innovative Production and Construction, Darwin, Australia, 3-5 October 2016.

45. Wohed, P.; van der Aalst, W.M.P.; Dumas, M.; ter Hofstede, A.H.; Russell, N. On the Suitability of BPMN for Business Process Modelling. In Proceedings of the International Conference on Business Process Management, Vienna, Austria, 4-7 September 2006; Springer: Berlin, Germany, 2006; pp. 161-176. [CrossRef]

46. Chinosi, M.; Trombetta, A. Modeling and Validating BPMN Diagrams; IEEE: Vienna, Austria, 2009; pp. 353-360. [CrossRef]

47. Dong, L.; Shan, J. A comprehensive review of earthquake-induced building damage detection with remote sensing techniques. ISPRS J. Photogramm. Remote Sens. 2013, 84, 85-99. [CrossRef]

48. Şen, Z. Rapid visual earthquake hazard evaluation of existing buildings by fuzzy logic modeling. Expert Syst. Appl. 2010, 37, 5653-5660. [CrossRef]

49. Jain, S.K. Multi Temporal Image Fusion of Earthquake Satellite Images. Int. J. Adv. Res. Comput. Sci. 2012, 3, 251-255.

Publisher's Note: MDPI stays neutral with regard to jurisdictional claims in published maps and institutional affiliations.

(C) 2020 by the authors. Licensee MDPI, Basel, Switzerland. This article is an open access article distributed under the terms and conditions of the Creative Commons Attribution (CC BY) license (http://creativecommons.org/licenses/by/4.0/). 